\title{
First report of leaf spot and stem canker on Malania oleifera caused by Neofusicoccum parvum in China
}

\author{
Yue Pan ${ }^{1}$ (D $\cdot$ Xiaoling Lei ${ }^{2} \cdot$ Pengfei Wang ${ }^{3} \cdot$ Guichai Yang $^{4} \cdot$ Yingjie $\mathrm{Gu}^{3} \cdot$ Ming Wang $^{3} \cdot$ Juan Wang ${ }^{1}$
}

Received: 11 May 2021 / Accepted: 15 October 2021 / Published online: 3 November 2021

(c) Società Italiana di Patologia Vegetale (S.I.Pa.V.) 2021

Keywords Neofusicoccum parvum $\cdot$ Leaf spot $\cdot$ Stem canker $\cdot$ Malania oleifera

Malania oleifera Chun \& S. K. Lee is an endemic economic tree species in China. During September 2019, brown leaf spots and stem cankers were observed on 3-year-old plants in Guangnan County, Yunnan Province. The disease incidence reached 5\%. Isolations were made from surface-disinfected symptomatic leaves and stems on potato dextrose agar (PDA) at $25^{\circ} \mathrm{C}$. Colonies were initially white, then turned dark-gray with a fluffy aerial mycelium. Globose conidiomata developed after 10 days on pine needle surfaces in synthetic low nutrient agar (SNA) and measured $0.88-1.32 \mathrm{~mm}$ in diameter. Conidia were hyaline, unicellular, fusiform to ellipsoidal, measuring 14.70-21.98 $\times 5.36-7.06 \mu \mathrm{m}(\mathrm{n}=50)$. Based on morphological characteristics, the fungus was identified as Neofusicoccum parvum (Pennycook \& Samuels) Crous, Slippers \& A.J.L. Phillips (Phillips et al. 2013). The internal transcribed spacer (ITS), the translation elongation factor $1-\alpha$ (EF1- $\alpha$ ) and the $\beta$-tubulin ( $\beta$-tub) regions of a representative isolate (CGMCC3.20367) were amplified using primers ITS1F/ITS4, EF1-728F/EF1-986R and BT-2a/BT-2b, respectively. The sequences of the representative isolate (GenBank accession Nos. MZ127652, MZ153110 and MZ153111) showed 99\% identity with the corresponding sequences of ex-type CMW 9081 of Botryosphaeria parva Pennycook

Juan Wang

schima@163.com

Yue Pan

panyue96@163.com

1 Eco-Development Academy, Southwest Forestry University, Kunming 650224, China

2 School of Geography and Ecotourism, Southwest Forestry University, Kunming 650224, China

3 College of Forestry, Southwest Forestry University, Kunming 650224, China

4 College of Garden and Horticulture, Southwest Forestry University, Kunming 650224, China
\& Samuels, now N. parvum (AY236943, AY236888 and AY236917). To confirm pathogenicity, $5 \mathrm{~mm}$ mycelial plugs of CGMCC 3.20367 were placed on leaves and $12 \mathrm{~cm}$ longstem segments wounded with sterile scalpels. Controls were inoculated with sterile PDA plugs. Each treatment had six repeats. They were then individually incubated in closed glass containers at $25{ }^{\circ} \mathrm{C}$ and $80 \%$ humidity. After 10 days, irregular spots and necrotic lesions appeared on all inoculated leaves and stems, while no disease symptoms developed in controls. The fungus was re-isolated only from symptomatic leaves and stems. To our knowledge, this is the first report of $N$. parvum causing leaf spot and stem canker on M. oleifera in China and worldwide (Farr and Rossmann 2021).

Acknowledgements This study was funded by the National Natural Science Foundation of China (No. 32160008), the Major Science and Technology Project of Yunnan Province (No. 202002AA10007) and the Special Project of Yunnan Province Ten Thousand Talents Plan--Yunling Industrial Technology Leading Talents (No.2018-212).

\section{Declarations}

Conflict of interest The author(s) declare no conflict of interest.

\section{References}

Farr DF, Rossman AY (2021) Fungal Databases, U.S. National Fungus Collections, ARS, USDA. Retrieved March 10, 2021

Phillips A, Alves A, Abdollahzadeh J, Slippers B, Wingfield MJ, Groenewald J, Crous PW (2013) The Botryosphaeriaceae: Genera and species known from culture. Stud Mycol 76:51-167. https:// doi.org/10.3114/sim0021

Publisher's Note Springer Nature remains neutral with regard to jurisdictional claims in published maps and institutional affiliations. 